\title{
Amino acids and phosphates stimulate hatching of Ochlerotatus koreicoides (Diptera: Culicidae) eggs
}

\author{
Ines Tomoco MATSUSE ${ }^{1)}$, Norio NAKAMURA ${ }^{2)}$, Purusotam BASNET ${ }^{2)}$, \\ Masao HATTORI $^{2)}$, Kiyoshi KAMIMURA ${ }^{1)}$ and Hisashi FUNADA ${ }^{1)}$ \\ 1) Department of Infectious Prophylaxis, Faculty of Medicine, Toyama Medical and Pharmaceutical \\ University, Toyama, 930-0194 Japan \\ ${ }^{2)}$ Institute of Natural Medicine, Toyama Medical and Pharmaceutical University, \\ Toyama, 930-0194 Japan
}

(Received: 15 February 2002; Accepted: 13 March 2002)

Key words: Ochlerotatus koreicoides, mosquito, hatch, glutamic acid, phosphates

\begin{abstract}
A tree-hole mosquito species, Ochlerotatus (Finlaya) koreicoides has been reared in laboratory by stimulating their hatch using dried yeast powder. This method shows to be more effective than lowering the dissolved oxygen concentration by mechanical, chemical or biological means. From a hatch test guided fractionation of the water extract of dried yeast, glutamic acid was isolated as the main compound of the hatch stimulating fraction. This amino acid alone did not show hatch stimulating effect but it was effective in combination with the phosphates that are also constituents of dried yeast. Among 20 amino acids, only histidine and proline showed similar effects as glutamic acid. A concentration of $0.1 \mathrm{mg} / \mathrm{ml}$ of each glutamic acid and trisodium phosphate gave high percentage hatch in $18 \mathrm{~h}$.
\end{abstract}

\section{INTRODUCTION}

Ochlerotatus (formerly genus Aedes) (Finlaya) koreicoides (Sasa, Kano and Hayashi), a tree-hole mosquito first recorded by Sasa et al. in 1950, is reared in our laboratory. The eggs are laid above the water line and the embryo develops in about 6 days up to the point of hatching, remaining in a state of suspended development until some stimulus leads to hatching. They do not hatch for months if conditioned in humid chamber or in distilled water. Many hatch stimulating agents for mosquitoes have been reported so far such as reducing agents (glutathione, cysteine, iron powder, etc.), microorganisms (bacteria, yeasts and molds), and vacuum (Thomas,1943; Barbosa and Peters, 1969). In the studies of the physiology of floodwater mosquitoes, Horsfall (1956) emphasized the importance of conditioning of eggs and the decreasing gradient of dissolved oxygen to stimulate hatching. The effect of dissolved oxygen in stimulating hatching was studied by polarographic determination using eggs of Aedes aegypti and Ae. nigromaculis (Judson, 1960). In the laboratory rearing of Oc. koreicoides (Arakawa et al., 1991), the eggs are stimulated to hatch using a few amount of 
dried yeast. In this case also, the hatching stimulus was thought to be the decrease of dissolved oxygen caused by chemical compounds or microbial growth until it was observed that the stimulus would be due to the presence of some specific substances in the medium. Moreover, the dried yeast stimulated the hatch of eggs submerged in continuously aerated water. The purpose of the present experiment was to identify the hatch stimulating substances contained in dried yeast.

\section{Materials AND METHODS}

\section{Mosquito}

Ochlerotatus koreicoides was colonized from some larvae collected in a beech tree-hole at an altitude $980 \mathrm{~m}$ of Mt. Tateyama, Toyama Prefecture, Japan. Larvae and pupae were raised under conditions of $25 \pm 1{ }^{\circ} \mathrm{C}$, relative humidity $70 \pm 5 \%$ and daily photoperiod of $14: 10 \mathrm{~h}$ (L:D). Adults were provided 3\% sucrose solution, and females were bloodfed for egg-laying. Eggs were collected in damp filter papers in a 250-ml cups placed inside of the colony cage. The collected eggs were incubated for at least one week to ensure embryonation. Dried yeast powder $(0.1 \mathrm{mg} / \mathrm{ml})$ was sprinkled over the water containing mature eggs for hatching. Larvae were reared on dried yeast added with liver and vegetable powder.

\section{Dried yeast and chemicals}

The dried yeast was purchased from Asahi Beer Pharmaceutical Co., Ltd., Japan. The compounds tested for mosquito hatching are listed in Table I. All compounds and reagents were purchased from Wako Pure Chemical Industries, Ltd., Japan.

Table I. Compounds tested to stimulate hatching of Ochlerotatus koreicoides eggs.

\begin{tabular}{ll}
\hline L-amino acids & alanine, arginine, asparagine, aspartic acid, cysteine, glutamic acid, \\
& glutamine, glycine, histidine, isoleucine, leucine, lysine, methionine, \\
& phenylalanine, proline, serine, threonine, tryptophan, tyrosine and valine. \\
\hline Inorganic salts & calcium chloride $\left(\mathrm{CaCl}_{2}\right) ;$ calcium phosphate, tribasic $\left[\mathrm{Ca}_{3}\left(\mathrm{PO}_{4}\right)_{2}\right] ;$ \\
& dipotassium hydrogen phosphate $\left(\mathrm{K}_{2} \mathrm{HPO}_{4}\right) ;$ disodium hydrogen \\
& phosphate $\left(\mathrm{Na}_{2} \mathrm{HPO}_{4}\right) ;$ magnesium sulfate $\left(\mathrm{MgSO}_{4}\right) ;$ potassium chloride \\
& $(\mathrm{KCl}) ;$ sodium chloride $(\mathrm{NaCl})$ and trisodium phosphate $\left(\mathrm{Na}_{3} \mathrm{PO}_{4}\right)$. \\
\hline Nucleosides & adenosine, cytidine, guanosine, inosine and thymidine. \\
\hline Sugars & D-arabinose, D-galactose, D-glucose, D-rhamnose and sucrose. \\
\hline Vitamins & ascorbic acid, biotin, folic acid, nicotinic acid, pyridoxine hydrochloride \\
\hline Others & and thiamine. \\
\hline
\end{tabular}

Isolation of hatch stimulating substance

Dried yeast powder (200 g) was suspended in distilled water $(2.0 \mathrm{l})$ and allowed to stand overnight at room temperature and then centrifuged. The supernatant was concentrated by 
rotatory evaporation and freeze-dried $(26.5 \mathrm{~g})$. The freeze dried extract is referred to as water extract. A portion $(1.0 \mathrm{~g})$ of the water extract was dissolved in water $(30 \mathrm{ml})$ and passed through a spin column VIVASPIN (Vivascience, UK) to separate into Fraction I (substances with molecular weight 5,000 or higher) and Fraction II (substances with smaller molecular weight). Both fractions showed hatch stimulating effects. With the aim to isolate and identify first the small molecules, Fraction II was further separated by chromatography. This was first chromatographed on an ion-exchange column (Amberlite IRA-400), pre-conditioned with 0.1 $\mathrm{N} \mathrm{NaOH}$. The column was washed with water followed by elution with $1.0 \mathrm{~N}$ formic acid to give an acidic fraction $(212.2 \mathrm{mg})$. The washings were then applied to a column of IR-120B, pre-conditioned with $0.1 \mathrm{~N} \mathrm{HCl}$. After washing with water to give a neutral fraction $(93.7 \mathrm{mg})$, the column was eluted with $10 \%$ aqueous ammonia to give a basic fraction $(82.5 \mathrm{mg})$. For further separation of the hatch stimulating substance, the acidic fraction was subjected to high performance liquid chromatography (HPLC) under the following conditions: column, Shodex Protein WS-2003 (20 x $300 \mathrm{~mm}$, Shoko Co., Ltd., Japan), eluted with water at a flow rate of $2.0 \mathrm{ml} / \mathrm{min}$ and detection at $260 \mathrm{~nm}$ (UV detector L-7400, Hitachi Ltd., Japan). Structural determination of glutamic acid was based on spectral analysis. Proton nuclear magnetic resonance $\left({ }^{1} \mathrm{H}-\mathrm{NMR}\right)$ spectrum was measured in deuterium oxide at room temperature on a Varian Unity Plus 500 spectrometer. The inorganic elements were determined by a scanning electron microscope (SEM) Hitachi SEMEDX III Type N.

\section{Hatch test}

Autoclaved distilled water was used throughout the hatch test. Mature eggs of equivalent ages were washed with water twice and transferred to a clean cup containing water. They were allowed to stand about $2 \mathrm{~h}$. Some larvae that hatched during this time were removed and only normal and unhatched eggs were selected under the stereomicroscope $(10 \mathrm{x}$ or $20 \mathrm{x}$ magnification) for experiment. Ten eggs of Ochlerotatus koreicoides were transferred to a glass vial. The test extracts or compounds were added and the volume was adjusted to $1.0 \mathrm{ml}$. All tests were conducted with six replicates. The vials were allowed to stand at $25^{\circ} \mathrm{C}$ and the hatched larvae were counted at $24 \mathrm{~h}$. Control tests were run with water and no more than $1.7 \%$ hatch in $72 \mathrm{~h}$ or over was observed.

\section{Statistical Analysis}

A multiple comparison Dunnett's test (SPSS 10.0 J for Windows base system) was used to determine the significant differences of the hatch stimulating effects among substances and control tests. 


\section{RESULTS}

Hatching of Ochlerotatus koreicoides eggs

Ochlerotatus koreicoides eggs have erratic hatching pattern, i.e. they do not hatch together even being all the same age. Therefore the maximum hatching rate observed in the tests averaged $90 \%$. Prior to the experiment with dried yeast, vacuum and agitation were tried to stimulate hatching. However, a very low percentage hatched by these methods, while 0.1 $\mathrm{mg} / \mathrm{ml}$ of dried yeast securely stimulated hatching of most of the eggs in $24 \mathrm{~h}$, with the first hatch starting at $8 \mathrm{~h}$.

The hatch stimulating substances from dried yeast

The hatch stimulating effects of dried yeast extract and fractions are shown in Table II. After separation of the water extract according to the molecular size, Fraction I showed a high percentage hatch $(86.7 \%)$ like the water extract $(90.0 \%)$. However, Fraction II (63.3\%), containing smaller molecules, was further separated through ion-exchange chromatography for the isolation of the active factor. A significant hatch stimulating effect was found in the acidic fraction, which was subsequently passed through a column of HPLC. The hatch stimulating effect $(75.0 \%)$ was found in the fraction eluted from 16 to $30 \mathrm{~min}$ (Fraction $\mathrm{A}$ ), in which glutamic acid was identified as the main organic compound. Then, commercial glutamic acid was used in the experiments. Glutamic acid alone, as well as the other constituents of the dried yeast tested (Table I) did not stimulate hatching, in a concentration of $0.1 \mathrm{mg} / \mathrm{ml}$. Taking into account that the dried yeast contains high percentage of sodium, potassium, calcium, and phosphorus, combinations of these elements with glutamic acid were tested. Among them, $\mathrm{Na}_{3} \mathrm{PO}_{4}$ or $\mathrm{K}_{2} \mathrm{HPO}_{4}$ in combination with glutamic acid gave the hatch stimulating effects comparable to the dried yeast. Both showed similar hatching rates in $24 \mathrm{~h}$, with the first hatch at $8 \mathrm{~h}$.

The major elements other than $\mathrm{C}$ and $\mathrm{O}$, present in the active fraction were $\mathrm{P}(4.9 \%), \mathrm{Ca}$ (4.0\%), $\mathrm{Na}(3.1 \%)$ and $\mathrm{K}(2.1 \%)$, determined by SEM.

Table II . Hatch stimulating effects of dried yeast extract and fractions

\begin{tabular}{lc}
\hline \multicolumn{1}{c}{ Fractions } & Percent Hatch (Mean \pm S.E.M.) \\
\hline Water extract & $90.0 \pm 5.5 *$ \\
Fraction I & $86.7 \pm 4.9 *$ \\
Fraction II & $63.3 \pm 6.7 *$ \\
Acidic fraction & $61.7 \pm 4.8 *$ \\
Basic fraction & $1.7 \pm 1.7$ \\
Neutral fraction & $20.0 \pm 4.5$ \\
Fraction A from HPLC & $75.0 \pm 9.9 *$ \\
Control (water) & $1.7 \pm 1.7$ \\
\hline
\end{tabular}

*, Significantly different from the control $(\mathrm{P}<0.05)$. 


\section{The effects of glutamic acid and other substances}

Various concentrations of glutamic acid were tested in the presence of $0.1 \mathrm{mg} / \mathrm{ml}$ of $\mathrm{Na}_{3} \mathrm{PO}_{4}$. The result is shown in Fig. 1. The concentrations of 0.05 and $0.1 \mathrm{mg} / \mathrm{ml}$ showed the highest percentage hatch by $18 \mathrm{~h}$ and this remained thereafter. Lower concentrations of 1.0 to $10.0 \mu \mathrm{g} / \mathrm{ml}$ stimulated the hatching to a rate significantly different from the control in $24-48$ h.

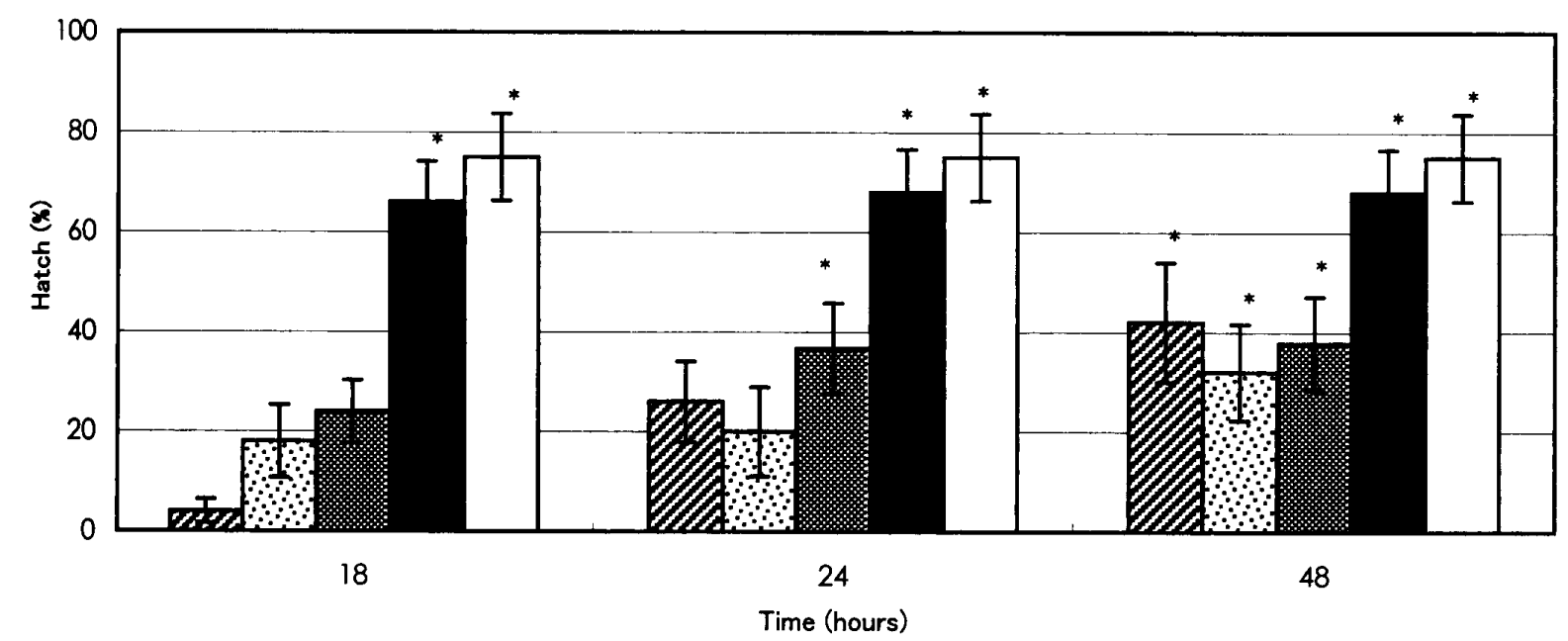

Fig. 1. Hatch stimulating effect of glutamic acid in the presence of trisodium phosphate $(0.1 \mathrm{mg} / \mathrm{ml})$. Control tests were run with water or any of the compounds alone. No hatch occurred in any of the control in $48 \mathrm{~h}$ or over. $\quad *$, Significantly different from the control $(\mathrm{P}<0.05)$.
Z, $0.001 \mathrm{mg} / \mathrm{ml} ; 0.005 \mathrm{mg} / \mathrm{ml}$;
闻, $0.01 \mathrm{mg} / \mathrm{ml}$;
, $0.05 \mathrm{mg} / \mathrm{ml}$
, $0.1 \mathrm{mg} / \mathrm{ml}$.

\section{Effects of other amino acids}

Other amino acids were tested in the presence of $\mathrm{Na}_{3} \mathrm{PO}_{4}$. Among 20 amino acids (Table I), histidine and proline stimulated hatching of $73.3 \%$ and $71.7 \%$, respectively, in $24 \mathrm{~h}$ and aspartic acid and glutamine, $68.3 \%$ and $78.8 \%$, respectively, in $48 \mathrm{~h}$. Other amino acids did not stimulate hatching under the same conditions.

\section{Effects of other phosphates}

The comparative effects of glutamic acid $(0.1 \mathrm{mg} / \mathrm{ml})$ in the presence of $0.1 \mathrm{mg} / \mathrm{ml}$ of $\mathrm{K}_{2} \mathrm{HPO}_{4}, \mathrm{Na}_{3} \mathrm{PO}_{4}$, calcium phosphate $\left[\mathrm{Ca}_{3}\left(\mathrm{PO}_{4}\right)_{2}\right]$ or phosphoric acid $\left(\mathrm{H}_{3} \mathrm{PO}_{4}, 0.01 \%\right)$ are shown in Fig. 2. The combination of glutamic acid with $\mathrm{Na}_{3} \mathrm{PO}_{4}$ or $\mathrm{K}_{2} \mathrm{HPO}_{4}$ gave a high percentage hatch by $18 \mathrm{~h}$. With calcium phosphate it was slower, the hatch starting around 24 $\mathrm{h}$ and with $\mathrm{H}_{3} \mathrm{PO}_{4}$ it required more time, reaching the maximum hatch at $48 \mathrm{~h}$. Although being slow they were effective if compared to the control with water, glutamic acid or phosphates alone that were not effective even after $72 \mathrm{~h}$. 


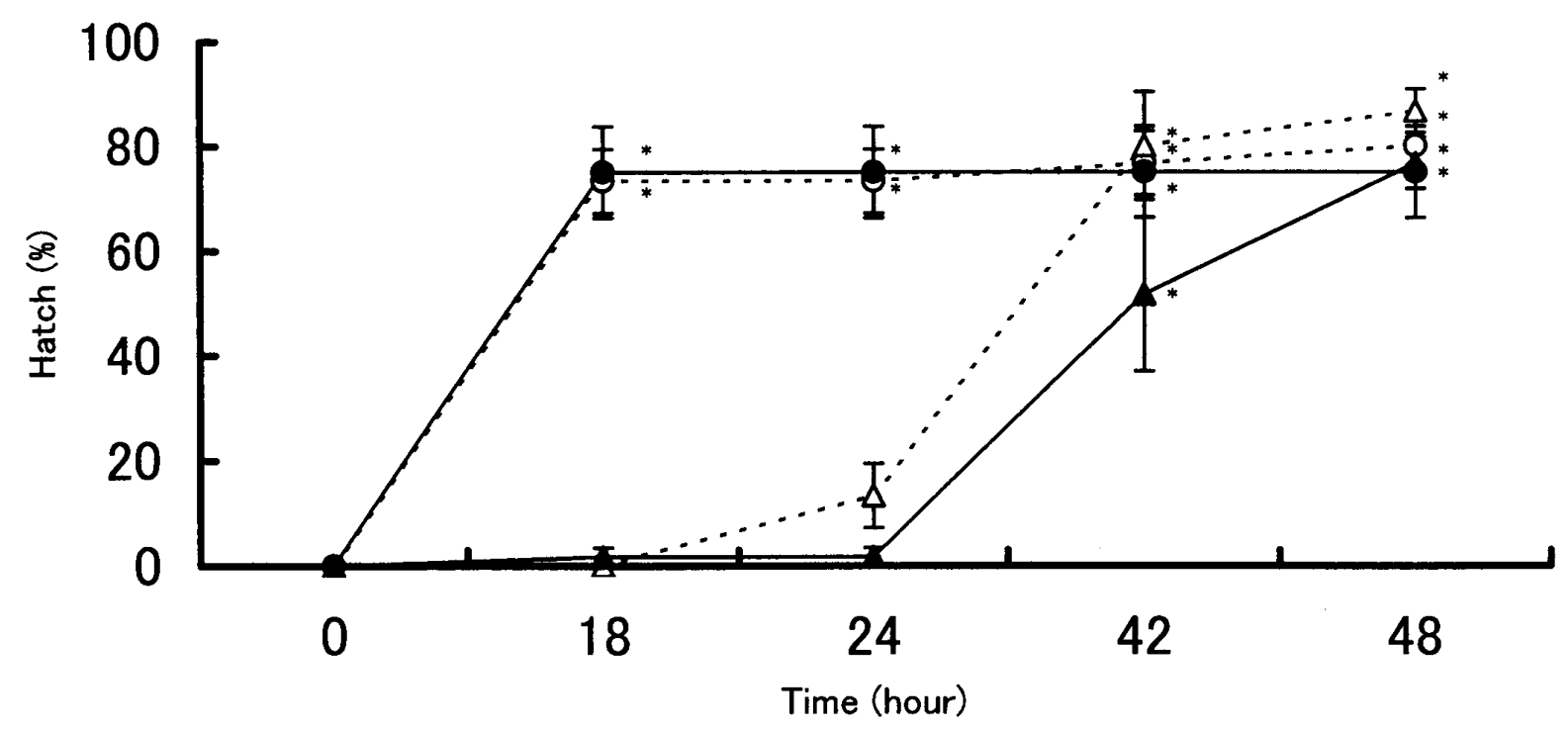

Fig. 2. Comparative effects of glutamic acid $(0.1 \mathrm{mg} / \mathrm{ml})$ in the presence of trisodium, dipotassium, calcium phosphates $(0.1 \mathrm{mg} / \mathrm{ml})$ and phosphoric acid $(0.01 \%)$. Control tests were run with water and each of compounds alone. No hatch occurred in any of the control in $48 \mathrm{~h}$ or over.

*, Significantly different from the control $(\mathrm{P}<0.05)$.

, glutamic acid + trisodium phosphate; $\bigcirc$, glutamic acid + dipotassium hydrogen phosphate;

$\triangle$, glutamic acid + calcium phosphate; $\quad \boldsymbol{\Lambda}$, glutamic acid + phosphoric acid.

\section{Discussion}

The mechanism of hatch of mosquito eggs is thought to be triggered by the decrease of dissolved oxygen in the water, that may be caused by chemical, physical or biological means, as was determined specially by Horsfal (1954) and Judson (1960). The hatching feature of Oc. koreicoides in our laboratory suggested that some substances present in the medium would have direct influence over hatching mechanism. The facts that led us to isolate the hatch stimulating substances of the dried yeast were: 1) the eggs of Oc. koreicoides did not hatch spontaneously in the laboratory even during microbial growth in the medium; 2) lowering the dissolved oxygen by chemical substances such as ascorbic acid and glutathione or by vacuum was not effective to stimulate hatching of this mosquito; 3 ) the dried yeast stimulated hatching in water under aeration.

The dried yeast was extracted with water and subjected to fractionations to identify the stimulating substances. The substance found in the active fraction of yeast extract was glutamic acid, which did not show activity alone but did in the presence of phosphate compounds. The stimulating effects of glutamic acid in the presence of $\mathrm{Na}_{3} \mathrm{PO}_{4}$ and $\mathrm{K}_{2} \mathrm{HPO}_{4}$ were shown to be faster than in the presence of $\mathrm{H}_{3} \mathrm{PO}_{4}$ or $\mathrm{Ca}_{3}\left(\mathrm{PO}_{4}\right)_{2}$. Many other compounds of dried yeast listed by the manufacturer were tested, including amino acids, vitamins, and inorganic salts, however they failed to stimulate hatching in isolated form. It was then found that glutamic acid is effective in combination with phosphates that are also present in dried 
Vol.53 Suppl.2, 2002

yeast. Other amino acids were also tested and some of them, but not all, stimulated hatching in combination with $\mathrm{Na}_{3} \mathrm{PO}_{4}$. The present result shows that the hatching of Oc. koreicoides does not take place simply by substances that remove dissolved oxygen by chemical replacement or serving as energy source for microbial growth. Moreover, eggs of Oc. (Finlaya) kobayashii, which has similar hatching features as Oc. koreicoides (Arakawa et al., 1991), and some pools of eggs of Aedes paullusi and Ae. albopictus that did not hatch spontaneously in our laboratory were stimulated with glutamic acid- $\mathrm{Na}_{3} \mathrm{PO}_{4}$ (data not shown).

The eggs had to be in contact with the hatch stimulating substances for over $6 \mathrm{~h}$ to start hatching. During this period of time the amino acids and inorganic elements would penetrate the egg to trigger the hatching mechanism. Glutamic acid plays important biochemical functions in living organisms. It is used as a neurotransmitter by many different neural systems and is believed to mediate most excitatory synaptic transmission in the mammalian brain (Standaert and Young, 1996). This is the major amino acid constituent of dried yeast and is widely found in nature. Proteins or other constituents of dried yeast with molecular size over 5,000 may be involved in the hatching mechanism, since Fraction I gave a high percentage hatch. However, the present result strongly suggests that small melecules such as some amino acids and phosphates present in the natural breeding sites play important roles besides the environmental factors on the hatching of Oc. koreicoides and other related species.

\section{ACKNOWLEDGEMENTS}

We thank Mr. Hideki Tsuboi and Mr. Masao Wada (Hitachi Science Systems, Ltd., Japan) for measuring the inorganic elements by SEM.

\section{REFERENCES}

Arakawa, R., Watanabe, M., Okazawa, T. and Kamimura, K. 1991. Hatch stimulation on the eggs of tree-hole mosquitoes Aedes kobayashii and Ae. koreicoides. Med. Entomol. Zool., 42: 212 (in Japanese).

Barbosa, P. and Peters, T. M. 1969. A comparative study of egg hatching techniques for Aedes aegypti (L.). Mosquito News, 29: 548-551.

Horsfall, W. R. 1956. Eggs of floodwater mosquitoes III (Diptera, Culicidae). Conditioning and hatching of Aedes vexans. Ann. Entomol. Soc. Amer., 49: 66-71.

Judson, C. L. 1960. The physiology of hatching of aedine mosquito eggs: hatching stimulus. Ann. Entomol. Soc. Amer. 53: 688-691.

Sasa, M., Kano, R. and Hayashi, S. 1950. A new species of mosquito, Aedes koreicoides n. sp., from Hokkaido. Japan. J. Exp. Med., 20: 627-629.

Standaert, D. G. and Young, A. B. 1996. Treatment of central nervous system degenerative disorders. In Goodman and Gilman's The Pharmacological Basis of Therapeutics. $9^{\text {th }}$ ed., J. G. Hardman and L.E. 
Limbird Ed., McGraw-Hill, USA.

Thomas, D. 1943. Preliminary studies on the physiology of Aedes aegypti. 1. The hatching of the eggs under sterile conditions. J. Parasit., 29: 324-328. 